\title{
SUPPORTED EMPLOYMENT AS A STRATEGY FOR ACCESS TO INCLUSIVE EMPLOYMENT FOR PEOPLE WITH DISABILITIES: A REVIEW
}

\author{
Esther Chiner ${ }^{1}$, Marcos Gómez-Puerta ${ }^{2}$, María-Cristina Cardona-Moltó ${ }^{1}$ \\ ${ }^{1}$ Department of Health Psychology, University of Alicante (Spain) \\ ${ }^{2}$ Department of Developmental Psychology and Teaching, University of Alicante (Spain)
}

\begin{abstract}
Unlike other training models, supported employment promotes training and adjustment to the job in the workplace itself. Supported employment is considered one of the most appropriate strategies to promote labour inclusion in ordinary companies, especially in the case of people with intellectual disabilities. Likewise, it favours the supply of supports of varying degrees of intensity in a longitudinal manner, as well as the establishment of natural supports among other co-workers. The objective of this study was to examine the scientific production on supported employment of people with disabilities through a bibliometric analysis. The sample of 717 documents on this subject was obtained from the core collection of the Web of Science (WoS). Data analysis was performed using the bibliometric tools available at the WoS website. The results indicate a great interest on this subject in the last decades, being reflected in a great scientific production. However, this seems to have partially slowed down since the economic crisis of 2008. This being a preliminary study, it is advisable to continue with the bibliometric analysis of the data in order to achieve a better perspective of what has been published so far.
\end{abstract}

Keywords: Disability, supported employment, inclusive workplace, bibliometrics, barriers.

\section{Introduction}

The 2030 Agenda for Sustainable Development (United Nations, 2015) establishes in target 10.2 of Sustainable Development Goal 4 (Quality education for all) the purpose of empowering and promoting the social, economic and political inclusion of all people regardless of their age, sex, disability, race, ethnicity, origin, religion or economic situation or other condition. As a consequence of the initiatives aimed at fighting their discrimination, in recent decades there has been progressively greater sensitivity in the workplace towards people with disabilities and other disadvantaged groups (Fisac, Moreno, Mataix, and Palacios, 2011). Despite the various political initiatives enacted, there is multiple evidence that people with disabilities are one of the groups most discriminated against by society, and this discrimination may manifest itself in various ways such as direct or indirect discrimination, failure to make reasonable adjustments in the environment, harassment or victimization (Equality and Human Rights Commission, 2018). Khayatzadeh-Mahani et al. (2019) have identified that there are barriers both in the person and in the environment that can limit access and participation in employment for people with disabilities. Supported employment has shown its effectiveness in terms of the results of, on the one hand, the access to and maintenance of the job and, on the other, the improvement of the person's quality of life (Frederick and VanderWeele, 2019). Furthermore, there is evidence that hiring people with disabilities brings specific benefits to companies (e.g. profits and cost-effectiveness, turnover and retention, reliability and punctuality, employee loyalty, company image) (Lindsay, Cagliostro, Albarico, Mortaji, and Karon, 2018). Until now, reviews of the literature on supported employment have focused on measuring its effectiveness (Cheng et al., 2018; Frederick and VanderWeele, 2019) or the impact on people with certain types of disability (Cheng et al., 2018; Khayatzadeh-Mahani et al., 2019). Nevertheless, a general bibliometric analysis has not been shown, a deficiency that this study tries to compensate. 


\section{Methods}

The purpose of this study was to examine the academic production on supported employment for people with disabilities in order to establish a preliminary overview of this area of study. This was done using a bibliometric methodology and a quantitative approach analysis to describe the evolution of research production, and productivity according to sources, authors, countries and affiliations.

\subsection{Data collection}

To obtain a report on the scientific production of inclusive work environments, one of the most academically relevant databases was accessed on March 11, 2021: the core collection of the Web of Science (WoS). The key terms used for the search were "supported employment" and "disabilit*". The asterisk used in the term disabilit* served to give valid forms of the word in singular (disability) and plural (disabilities). The Boolean AND connector was used to select those documents that included both terms (inclusive employment AND disability/ies). The search allowed locating these terms in the title, the keywords and abstract of the document. There were no restrictions on time period or language. In order to refine the data, a series of criteria were applied. In the first place, only documents belonging to the field of Social Sciences were chosen. Second, only the publications belonging to the WoS core collection were selected. Finally, we chose only articles and reviews as valid documents for this study, as reflected in the following flow diagram.

Figure 1. Data collection and filtering flow diagram.

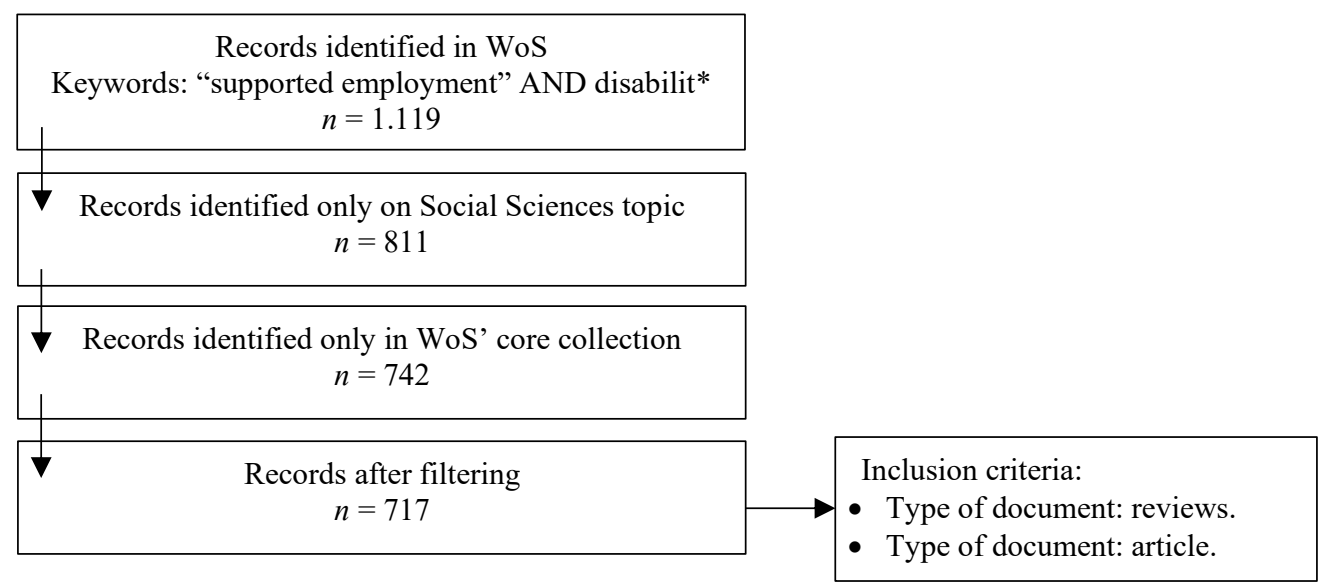

\subsection{Data analysis}

Once the data was compiled, these were analysed using the bibliometric analysis tools available in WoS. Consistent with the objectives of the study, production was described by year, by source, by author, and impact by country, institution, source, author, and document. The 717 documents corresponded to 592 articles (82.56\%) and 125 reviews (14.44\%). Most of the documents were written in English $(n=692 /$ $96.5 \%)$.

\section{Results}

The results are presented in subsections according to the order of planned research objectives: scientific production, production by sources, production by the authors, and production by country and affiliation.

\subsection{Evolution of the scientific production by year}

The production ranges from 1988 to the present, 2021, as can be seen in the data reflected in figure 2. Publications are registered every year since the beginning in 1988. In addition, the data reflect a progressive increase in papers on this subject, reaching production limits in $2018(n=59 / 8.2 \%)$ and 2014 $(\mathrm{n}=49 / 6.8 \%)$. Despite this general increase trend in production, striking productivity valleys can be observed from 2015 to 2017 and from 2019 to the present. Likewise, a productive plateau can be observed between 2008 and 2012, probably the worst years of the global financial crisis. 


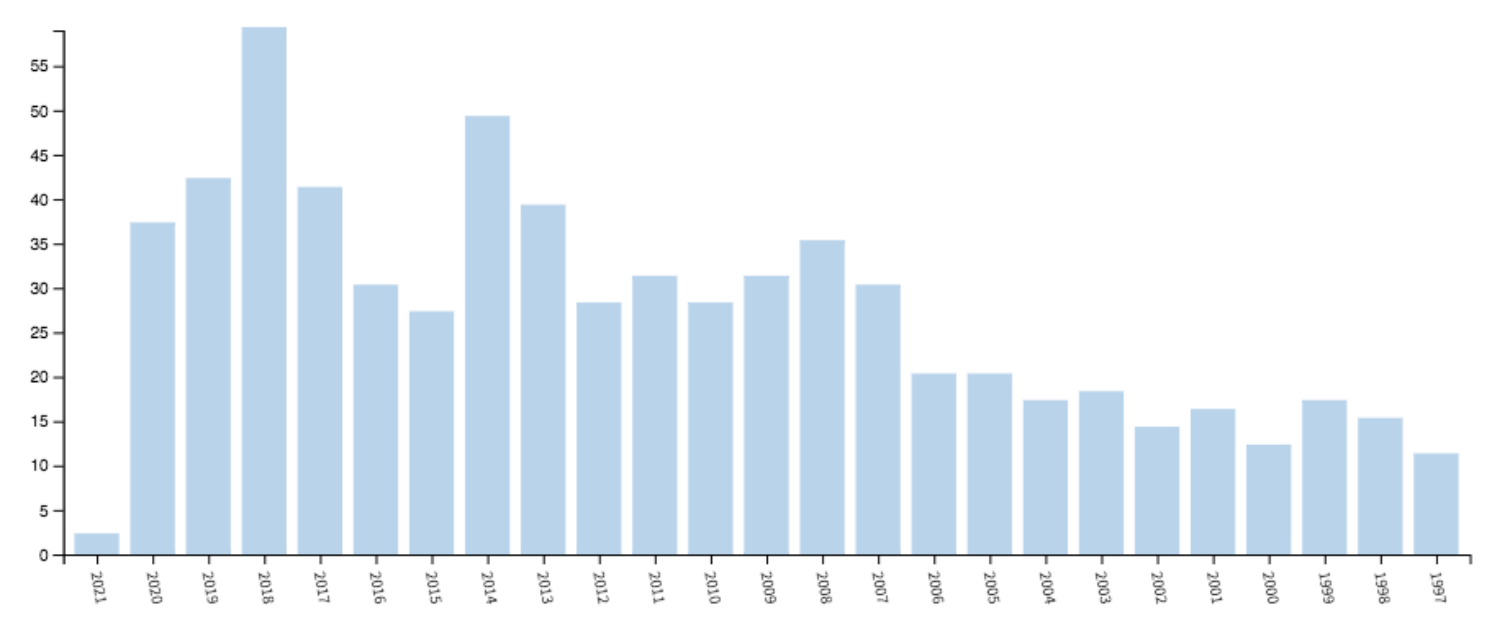

\subsection{Sources' productivity}

The most relevant sources in terms of the number of publications on the subject analysed are Psychiatric Rehabilitation Journal $(n=56)$, Psychiatric Services $(n=36)$ and Psychiatric Services Washington D C $(n=36)$, as reflected in Table 1.

Table 1. Main Source Productivity.

\begin{tabular}{lc}
\hline Sources & Documents \\
\hline Psychiatric Rehabilitation Journal & 56 \\
\hline Psychiatric Services & 36 \\
\hline Psychiatric Services Washington D C & 36 \\
\hline Work A Journal Of Prevention Assessment Rehabilitation & 33 \\
\hline Work Reading Mass & 33 \\
\hline Journal Of Applied Research In Intellectual Disabilities & 26 \\
\hline Mental Retardation & 22 \\
\hline Education And Training In Mental Retardation And & 18 \\
Developmental Disabilities & \\
\hline Disability And Rehabilitation & 17 \\
\hline Journal Of Occupational Rehabilitation & 15 \\
\hline
\end{tabular}

\subsection{Authors' scientific production}

Regarding the production by authors, R. E. Drake and G. R. Bond are the most prolific in this field, having published 111 and 85 articles, respectively. The rest of the authors among the 10 most productive have published in a range of 10 to 38 articles (Table 2).

Table 2. Most relevant authors.

\begin{tabular}{lc}
\hline Authors & Documents \\
\hline Drake, R. E. & 111 \\
\hline Bond, G. R. & 85 \\
\hline Becker, D. R. & 38 \\
\hline Mueser, K. T. & 37 \\
\hline Rogers, E. S. & 30 \\
\hline Waghorn, G. & 28 \\
\hline Cook, J. A. & 22 \\
\hline Wehman, P. & 21 \\
\hline Beyer, S. & 10 \\
\hline Cimera, R. E. & 10 \\
\hline
\end{tabular}

The 10 most relevant articles by the number of citations they have received since they were published are reflected in table 3 . 
Table 3. Most cited documents.

\begin{tabular}{|c|c|c|}
\hline Paper & TC & TC per year \\
\hline Mueser, K. T. \& McGurk, S. R. (2004). Schizophrenia. Lancet, 363(9426), 2063-2072. & 610 & 33.89 \\
\hline $\begin{array}{l}\text { Lehman, A., et al. (2004). The Schizophrenia Patient Outcomes Research Team (PORT): } \\
\text { Updated Treatment Recommendations 2003. Schizophrenia Bulletin, 30(2), 193-217. } \\
\text { https://doi.org/10.1093/oxfordjournals.schbul.a007071 }\end{array}$ & 393 & 21.83 \\
\hline $\begin{array}{l}\text { Rosenheck, R., L et al. (2006). Barriers to employment for people with schizophrenia. The } \\
\text { American journal of psychiatry, 163(3), 411-417. } \\
\text { https://doi.org/10.1176/appi.ajp.163.3.411 }\end{array}$ & 298 & 18.63 \\
\hline $\begin{array}{l}\text { Bond, G. R., Drake, R. E., Mueser, K. T., \& Becker, D. R. (1997). An update on supported } \\
\text { employment for people with severe mental illness. Psychiatric services (Washington, } \\
\text { D.C.), } 48(3), 335-346 . \text { https://doi.org/10.1176/ps.48.3.335 }\end{array}$ & 248 & 9.92 \\
\hline $\begin{array}{l}\text { Krause, N., Dasinger, L., \& Neuhauser, F. (1998). Modified Work and Return to Work: A } \\
\text { Review of the Literature. Journal of Occupational Rehabilitation, 8(2), 113-139. } \\
\text { https://doi.org/10.1023/A:1023015622987 }\end{array}$ & 221 & 9.21 \\
\hline $\begin{array}{l}\text { Cook, J. A., et al. (2005). Results of a multisite randomized trial of supported employment } \\
\text { interventions for individuals with severe mental illness. Archives of general psychiatry, } \\
62(5), 505-512 . \mathrm{https} / / \text { doi.org/10.1001/archpsyc.62.5.505 }\end{array}$ & 197 & 11.59 \\
\hline $\begin{array}{l}\text { Stuart H. (2006). Mental illness and employment discrimination. Current opinion in } \\
\text { psychiatry, 19(5), 522-526. https://doi.org/10.1097/01.yco.0000238482.27270.5d }\end{array}$ & 166 & 10.38 \\
\hline $\begin{array}{l}\text { Dunn, E. C., Wewiorski, N. J., \& Rogers, E. S. (2008). The meaning and importance of } \\
\text { employment to people in recovery from serious mental illness: results of a qualitative } \\
\text { study. Psychiatric rehabilitation journal, 32(1), 59-62. } \\
\text { https://doi.org/10.2975/32.1.2008.59.62 }\end{array}$ & 161 & 11.50 \\
\hline $\begin{array}{l}\text { Harvey, P. D., Velligan, D. I., \& Bellack, A. S. (2007). Performance-based measures of } \\
\text { functional skills: usefulness in clinical treatment studies. Schizophrenia bulletin, 33(5), } \\
\text { 1138-1148. https://doi.org/10.1093/schbul/sbm040 }\end{array}$ & 161 & 10.73 \\
\hline $\begin{array}{l}\text { Mueser, K. T., et al. (2004). The Hartford study of supported employment for persons with } \\
\text { severe mental illness. Journal of consulting and clinical psychology, 72(3), 479-490. } \\
\text { https://doi.org/10.1037/0022-006X.72.3.479 }\end{array}$ & 161 & 8.94 \\
\hline
\end{tabular}

\subsection{Country and affiliation productivity}

The most productive countries in terms of scientific publications are the United States of America with 417 documents (58.15\%), Australia with 69 (9.6\%), Canada with 55 (7.6\%) and the United Kingdom with $53(7.4 \%)$.

Figure 3. Scientific production by countries.

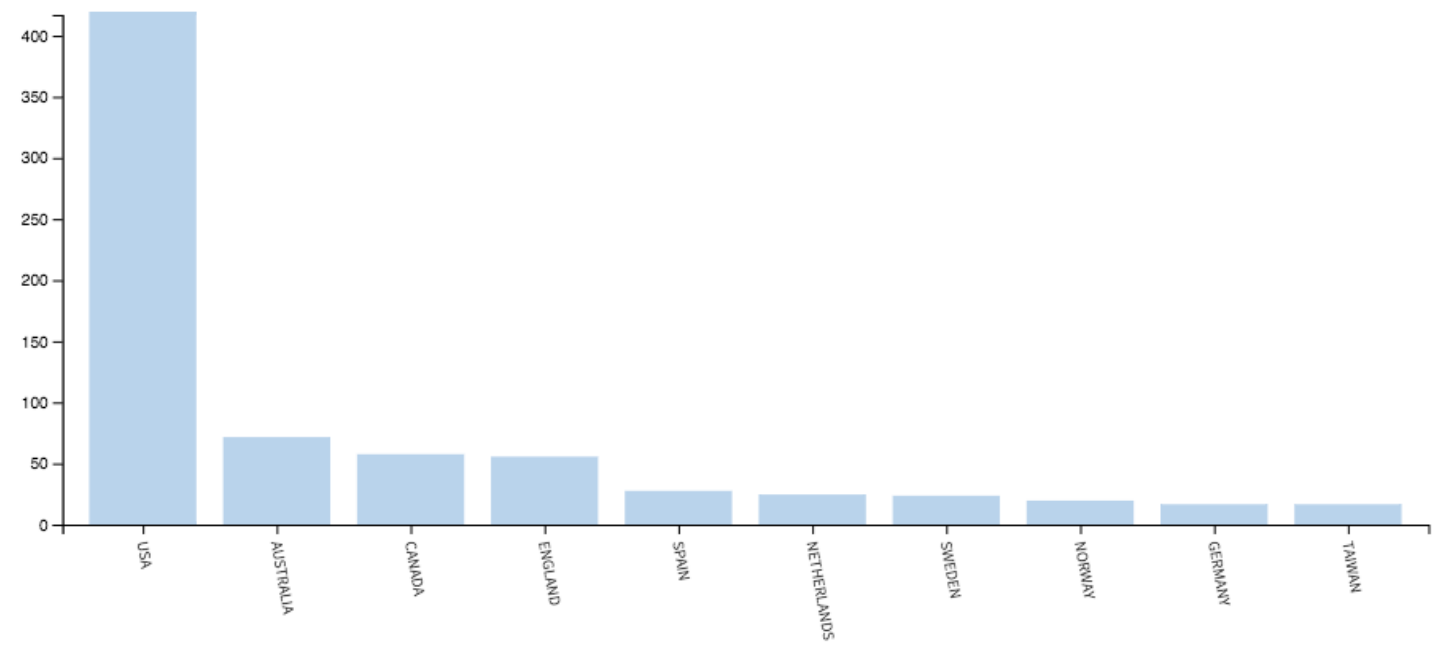

The affiliations that have published more academic papers in the WoS core collection are, coherently with productivity by country, institutions from the United States of America. In particular, the most productive are Boston University, Dartmouth College and the US Department of Veterans Affairs. 
Table 4. Most relevant affiliations according to their academic productivity.

\begin{tabular}{lc}
\hline Affiliation & Documents \\
\hline Boston University & 74 \\
\hline Dartmouth College & 55 \\
\hline US Department of Veterans Affairs & 43 \\
\hline Veterans Health Administration & 40 \\
\hline University of Illinois System & 35 \\
\hline Indiana University System & 29 \\
\hline Virginia Commonwealth University & 29 \\
\hline University System of Maryland & 27 \\
\hline Yale University & 27 \\
\hline University of California System & 24 \\
\hline University of Illinois & 23 \\
\hline
\end{tabular}

\section{Discussion and conclusions}

The data obtained on the WoS academic productivity show that there is a broad and sustained interest from the scientific community about supported employment as a strategy for accessing and maintaining the job. This interest seems to be especially prominent in the case of people with intellectual disabilities or mental illness, groups that are especially discriminated against in hiring (World Health Organization, 2011). One evidence of this is that the three most cited articles address specific supports for people with schizophrenia. Likewise, the high productivity of the United States of America and their institutions, and of R. E. Drake and G. R. Bond as authors stands out. On the other hand, the analysis of the number of annual publications seems to indicate the sensitivity of this topic to financial crises. In conclusion, this study has shown that supported employment has captured the interest of researchers in the last 30 years, especially in Anglo-Sphere countries. However, the number of studies should be expanded in the European Union.

This study has a series of limitations that must be taken into account when interpreting its results. First, there may be relevant publications not included in the WoS core collection and that, therefore, have not been included in this analysis. Second, only papers belonging to the Social Sciences have been analysed. Finally, the use of a limited number of terms in the search could have omitted certain articles that used other concepts. Future bibliometric investigations could try to compensate for these limitations by carrying out such analyses.

\section{Acknowledgments}

Cátedra Aguas de Alicante de Inclusión Social (University of Alicante, Spain).

\section{References}

Cheng, C., Oakman, J., Bigby, C., Fossey, E., Cavanagh, J., Meacham, H., and Bartram, T. (2018). What constitutes effective support in obtaining and maintaining employment for individuals with intellectual disability? A scoping review. Journal of Intellectual and Developmental Disability. Routledge. https://doi.org/10.3109/13668250.2017.1327040

Equality and Human Rights Commission. (2018). Disability discrimination. Retrieved 8 January 2019, from https://www.equalityhumanrights.com/en/advice-and-guidance/disability-discrimination

Fisac, R., Moreno, A., Mataix, C., and Palacios, M. (2011). La empresa social: revisión de conceptos y modelo para el análisis organizativo. Revista Española Del Tercer Sector, 17, 41-66.

Frederick, D. E., and VanderWeele, T. J. (2019). Supported employment: Meta-analysis and review of randomized controlled trials of individual placement and support. PLoS ONE, 14(2). https://doi.org/10.1371/journal.pone.0212208

Khayatzadeh-Mahani, A., Wittevrongel, K., Nicholas, D. B., and Zwicker, J. D. (2019). Prioritizing barriers and solutions to improve employment for persons with developmental disabilities. Disability and Rehabilitation, 42(19), 2696-2706. https://doi.org/10.1080/09638288.2019.1570356

Lindsay, S., Cagliostro, E., Albarico, M., Mortaji, N., and Karon, L. (2018). A Systematic Review of the Benefits of Hiring People with Disabilities. Journal of Occupational Rehabilitation. Springer New York LLC. https://doi.org/10.1007/s10926-018-9756-z

United Nations. Transforming our world: the 2030 Agenda for Sustainable Development, Pub. L. No. A/RES/70/1, 1 (2015). General Assembly.

World Health Organization. (2011). World Report on Disability. Geneva: World health Organization. 